\title{
Enhanced Performance of an Affinity Biosensor Interface Based on Mixed Self-Assembled Monolayers of Thiols on Gold
}

\author{
F. Frederix, ${ }^{*, \dagger}$ K. Bonroy, ${ }^{\dagger}$ W. Laureyn, ${ }^{\dagger}$ G. Reekmans, ${ }^{\dagger}$ A. Campitelli, ${ }^{\dagger}$ \\ W. Dehaen, $\neq$ and G. Maes ${ }^{\ddagger}$ \\ IMEC, MCP-BIO, Kapeldreef 75, B-3001 Heverlee, Belgium, and KULeuven, Physical and \\ Analytical Chemistry Department, Cel estijnenlaan 200F , 3001 Heverlee, Belgium
}

Received November 26, 2002. In Final Form: February 20, 2003

\begin{abstract}
An affinity biosensor interface of a biosensor is the interface between the sample and the transducer surface and is therefore of the utmost importance for the general performance of a biosensor. For immunosensor applications the affinity biosensor interface consists of antibodies, which are preferably coval ently attached to the transducer surface. In this paper the properties and the enhanced performance of an affinity biosensor interface based on mixed self-assembled monol ayers (SAMs) on gol d are discussed. Mixed SAM s consist of two different functionalities, which allow attachment of bi oreceptor molecules and avoid nonspecific adsorption. I n this work, mixed SAMs of thiols with carboxylic and hydroxyl or poly(ethylene glycol) groups are characterized with contact angle measurements, cyclic voltammetry, and grazing-angle F ourier transform infrared spectroscopy. It is found that the various mixed SAMs exhibit acceptablecoverageand structural properties. M ost importantly, surface plasmon resonancemeasurements clearly show the enhanced performance of these mixed SAMs with regard to sensitivity, stability, and selectivity compared to commercially available affinity biosensor interfaces. This superiority is experimentally demonstrated by evaluating the amount of immobilized antibodies, the recognition of antigens by the immobilized antibody, and the nonspecific adsorption of IgG molecules on the antibody-coated surfaces.
\end{abstract}

\section{Introduction}

Biosensors provide a rapid and convenient alternative to conventional analytical methods for monitoring (bio)chemical substances in various fields such as medicine, environment, fermentation, and food processing. ${ }^{1-3} \mathrm{~A}$ biosensor basically consists of two parts, i.e., an affinity biosensor interface and a transducer. Since the affinity biosensor interface constitutes the interface with the sample, this component mainly determines thespecificity, the reproducibility, and the stability of the whole sensor. In addition, nonspecific signals due to interferents constitute a major problem in diagnostic applications, where an analytein a low concentration has to bedetected in the presence of a much larger concentration of nonspecific molecules. The construction of a specificand stableaffinity biosensor interface is therefore mandatory for real biosensor applications.

The development of techniques for immobilization of the biomaterials plays a significant role in the biosensor research. ${ }^{4}$ The immobilization process not only ensures the intimate contact of the biological entities with the transducer but also aids in the stabilization of the biological system, enhancing its operational and storage stability. A number of methods have been applied for the

* To whom correspondence may be addressed: phone, +32-16288013; fax, +32-16-281097; e-mail, frederix@imec.be.

† IMEC, MCP-BIO.

₹ KULeuven.

(1) Mulchandani, A.; Rogers, K. R. Enzymeand Microbial biosensors: Techniques and Protocols; Humana: Totowa, NY, 1998.

(2) Ramsay, G. Commercial Biosensors: Applications to Clinical Bioprocess and Environmental Samples; J ohn Wiley \& Sons: London, 1998.

(3) Nikolelis, D.; Krull, U.; Wang,J .; Mascini, M. Biosensors for Direct Monitoring of Environmental Polluants in Field; Kluwer Academic: London, 1998.

(4) D'Souza, S. F. Appl. Biochem. Biotechnol. 2001, 96, 225. immobilization of receptor biomolecules, $, 5,6$ e.g., adsorption, ${ }^{7}$ covalent attachment to silanes, ${ }^{8}$ embedding in polymers, ${ }^{9,10}$ and membranes. ${ }^{11}$

We have recently developed an affinity biosensor interface based on the use of mixed self-assembled monolayers (SAMs) of thiols on gold. Thiol compounds are known for their stable bond to gold and for their reproduciblebehavior. ${ }^{12}$ They may beused in applications such as electroanalytical chemistry, 13,14 molecular electronics, ${ }^{15}$ corrosion research, ${ }^{16,17}$ biomaterial research, $, 4,18$ etc. In our approach, one of the thiols in the mixed SAM carries a functional group to attach the probe molecule, which is an antibody in immunosensor applications. The other thiol compound used for themixed SAM construction is known to be adequate for limiting the nonspecific adsorption of undesired biological entities. ${ }^{19-23}$ Thelatter

(5) Cass, T.; Ligler, F. S. I mmobilized Biomolecules in Analysis: A practical Approach; Oxford University Press: New York, 1998.

(6) Hermanson, G. T.; Mallia, A. K. Immobilized Affinity Ligand Techniques; Academic Press: London, 1992.

(7) Castner, D. G.; Ratner, B. D. Surf. Sci. 2002, 500, 28.

(8) Laureyn, W. Physicochemical study on the use of silanes for the realization of oxide-based biosensor interfaces. Ph.D. Thesis, KUL Luven, Belgium, 2002.

(9) Huang, N.-P.; Vönös, J .; De Paul, S. M.; Textor, M.; Spencer, N. D. Langmuir 2002, 18, 220.

(10) Cosnier, S. Biosens. Bioel ectron. 1999, 14, 443

(11) Cooper, M. A. Nat. Rev. 2002, 1, 515.

(12) Ulman, A. An Introduction toUItrathin OrganicFilms; Academic Press: San Diego, CA, 1991.

(13) Mandler, D.; Turyan, I. Electroanalysis 1996, 8 (3), 207.

(14) Bard, A. J .; Abruña, H. D.; Chidsey, C. E.; Faulkner, L. R.; Feldberg, S. W.; I taya, K.; Majda, M.; Melroy, O.; Murray, R. W.; Porter M. D.; Soriaga, M. P.; White, H. S. J . Phys. Chem. 1993, 97, 7147.

(15) Matsui, H.; Porrata, P.; Douberly, G. E. NanoLett. 2001, 1 (9), 461.

(16) J ennings, G. K.; Munro, J . C.; Laibinis, P. E. Adv. Mater. 1999, 11 (12), 1000.

(17) Laibinis, P. E.; Whitesides, G. M.J . Am. Chem. Soc. 1992, 114, 9022.

(18) Kasemo, B. Surf. Sci. 2002, 500, 656 
thiol carries hydrophilic end groups such as hydroxyl or poly(ethylene glycol). The incorporation of both thiols in a mixed SAM enables theattachment of receptor mol ecules and induces specific interaction of the immobilized anti bodies instead of a nonspecific adsorption of undesired biospecies on the surface. In this study, the antibodies are coupled by random, covalent coupling procedures in a direct or an indirect way via streptavidin and biotin. ${ }^{6}$

The antibody - antigen system applied to demonstrate thebiosensor potential of thesemixed SAM sisanti-human serum al bumin (anti-HSA)-human serum al bumin (HSA). It is well-known that the concentration of HSA in urine increases up to several hundred $\mu \mathrm{g} / \mathrm{mL}$ in thecase of kidney trouble. This implies that a urinary level in the order of several tens of $\mu \mathrm{g} / \mathrm{mL}$ can be a marker for the diagnosis of diabetic nephrosis. ${ }^{24}$ In addition, this anti-HSA/HSA system is chosen as a cost-effective reference system for other antibody-antigen interactions.

\section{Experimental Section}

Materials and Methods. All materials and reagents were used as commercially received. Anti-human serum al bumin (A0433), human serum al bumin (A-1653), human IgG reagent (I2511), streptavidin (S-4762), 1-ethyl-3-(3-(dimethylamino)propyl)carbodiimide (EDC), and N-hydroxysuccinimide (NHS) were obtained from Sigma. Biotinylated anti-human serum albumin was obtained from Biotrend Chemicalien $\mathrm{Gmbh}$, while 11-mercapto-1-undecanol (11-MUOH) (>97\%) and 16-mercapto1-hexadecanoic acid (16-MHA) (>90\%) were purchased from Aldrich. Ultrapureethanol was purchased from Riedel-DeH aën. Gold substrates mounted in chip (| 1-chip) and the dextran-coated gold substrates (CM5-chip) were purchased from Biacore. NMR spectra wereacquired on a B ruker Avance $300 \mathrm{MHz}$ spectrometer. Chemical shifts $(\delta)$ are reported in parts per million referenced to internal residual solvent protons $\left({ }^{1} \mathrm{H}\right)$ or the carbon signal of deuterated solvents $\left({ }^{13} \mathrm{C}\right)$. Mass spectroscopy data were obtained with an HP MS apparatus 5989A (chemical ionization $(\mathrm{Cl}), \mathrm{CH}_{4}$ ) and with a MSSOTC KRATOS doublefocusing mass spectrometer in electron impact with perfluorokerosene as a reference compound under full magnetic scan mode.

Preparation of Gold Substrates and Mixed SAMs. J 1 chips wereused as received and wereimmersed in the appropriate mixtures $(\mathrm{v} / \mathrm{v})$ of thiol solutions of $1 \mathrm{mM}$ in ethanol immediately after opening. Thereported mixtures are the percentages of thiols with carboxylicgroups in themixed thiol sol ution. After deposition for $3 \mathrm{~h}$, the substrates were thoroughly rinsed with ethanol and dried under a stream of nitrogen. Initially, the deposition time was varied between $10 \mathrm{~min}$ and $24 \mathrm{~h}$ and a duration of $3 \mathrm{~h}$ was found to be optimal. The gold films for grazing angle F ourier transform infrared, contact angle, and cyclic voltammetry measurements were deposited by electron beam evaporation of $10 \mathrm{~nm} \mathrm{Ti}$ and $100 \mathrm{~nm}$ Au on a polished 6' Si wafer with $1.2 \mu \mathrm{m}$ thermally grown $\mathrm{SiO}_{2}$.

Surface Plasmon Resonance Spectroscopy. The surface plasmon resonanceinstrument was a Biacore $2000,{ }^{25,26}$ provided with aJ 1-chip or CM5-chip. Theimmobilization degree of proteins

(19) Chapman, R. G.; Ostuni, E.; Yan, L.; Whitesides, G. M. Langmuir 2000, 16, 6927

(20) Ostuni, E.; Yan, L.; Whitesides, G. M. Colloids Surf., B 1999, $15,3$.

(21) Wang, R. L. C.; Kreuzer, H. J .; Grunze, M. J . Phys. Chem. B 1997, 101, 9767

(22) Lindblad, M.; Lestelius, M.;J ohansson, A.; Tengvall, P.; Thomsen, P. Biomaterials 1997, 18 (15), 1059.

(23) Silin, V.; Weetall, H.; Vanderah, D. J . J . Colloid Interface Sci. 1997, $185,94$.

(24) Sakai, G.; Saiki, T.; Uda, T.; Miura, N.; Yamazoe, N. Sens. Actuators, B 1995, 24-25, 134

(25) Stenberg, E.; Persson, B.; Roos, H.; Urbaniczky, C. J . Colloid Interface Sci. 1991, 143 (2), 513.

(26) J önsson, U.; Fägerstam, L.; I varsson, B.; J ohnsson, B.; Karlsson, R.; Lundh, K.; Löfăs, S.; Persson, B.; Roos, H.; Rönnberg, I.; Sjölander, S.; Stenberg, E.; Ståhl berg, R.; U rbaniczky, C.; Östlin, H.; Malmqvist, M. BioTechniques 1991, 11 (5), 620. in a Biacore surface plasmon resonance system is given in refractive units (RU). RU corresponds to a shift in resonance angle of approximately 0.1 millidegree.26 Immobilization of antibodies was accomplished via coupling to their primary amines. A continuous flow of Hepes buffered saline or HBS (10 $\mathrm{mM}$ 4-(2-hydroxyethyl)pi perazine-1-ethanesulfonicacid, $150 \mathrm{mM}$ $\mathrm{NaCl}, 3.4 \mathrm{mM}$ ethylenediami netetraacetate, and $0.005 \%$ Tween 20 $(\mathrm{pH} 7.4))$ at $5 \mu \mathrm{L} / \mathrm{min}$ was maintained during the immobilization period. All experiments were carried out at $25^{\circ} \mathrm{C}$. In detail, the carboxylic groups of the mixed SAMs were activated by injection of a solution containing different concentrations of NHS and EDC in deionized water. Next, $132 \mu \mathrm{L}$ of the antibody solution $(500 \mu \mathrm{g} / \mathrm{mL}$ in $10 \mathrm{mM}$ acetatebuffer $\mathrm{pH} 5.0)$ wasinjected, followed by injection of $50 \mu \mathrm{L}$ of $1.0 \mathrm{M}$ ethanolamine in order to block remaining NHS ester groups and by two $10 \mu \mathrm{L}$ injections of 10 $\mathrm{mM}$ glycine ( $\mathrm{pH} 2.2$ ) in order to remove nonspecifically bound molecules from the surface.

Antigens were diluted in HBS buffer to the concentrations applied and were then perfused over the antibody-immobilized surface at a flow rate of $20 \mu \mathrm{L} / \mathrm{min}$. After $6.5 \mathrm{~min}$ of association, the sampl esolution was replaced by a HBS buffer flow for $7 \mathrm{~min}$, allowing the compl ex to di ssociate. Regeneration of the surfaces was performed by two pulses of $10 \mathrm{mM}$ glycine (pH 2.2) between each analyte injection. The degree of binding was calculated by measuring the response signal at the end of the dissociation phase. The occurrence of nonspecific binding was measured by using $10 \mu \mathrm{g} / \mathrm{mL}$ IgG as the analyte.

Grazing Angle Fourier Transform Infrared Spectroscopy. The mixed SAM s on gold wereanalyzed with grazing angle F ourier transform infrared spectroscopy (GA-FTIR) on a Mattson Galaxy series FTIR 7000, using a Spectra-Tech FT 85 accessory, over a wavenumber range of $5000-600 \mathrm{~cm}^{-1}$. The spectra are the result of a Fourier transform of 8960 interferometric scans at a resolution of $2 \mathrm{~cm}^{-1}$ on three different samples, which are subsequently averaged. The background sample was a SAM of $\mathrm{HS}-\left(\mathrm{CD}_{2}\right)_{17}-\mathrm{CD}_{3}$ on gold. This deuterated thiol, which is mandatory to perform this kind of FTIR measurement, 19 was kindly supplied by the research group of Professor M. Grunze, Heidel berg, Germany.

Contact Angle Measurements. Contact angle measurements (CA) were performed on $1 \mu \mathrm{L}$ sessile drops of ultrapure water with an OCA 20 system from Dataphysics using SCA 20 software. Reported CA values are averaged over at least nine measurements, and the reported errors are 1 standard deviation.

Cyclic Voltammetry. The cyclic voltammetry (CV) experiments were performed with a homemade electrochemical cell with a Pt counter electrode and an $\mathrm{Ag} / \mathrm{AgCl}$ micro reference electrode from Microelectrodes, Inc. The setup uses a Gamry Instruments potentiostat with Framework software. All experiments were performed in a $6 \mathrm{mM} \mathrm{K}{ }_{3} \mathrm{Fe}(\mathrm{CN})_{6}$ solution with $1 \mathrm{M}$ $\mathrm{KCl}$ as the background electrolyte.

Synthesis of 2-(2-(2-(6-Mercaptohexyloxy)ethoxy)ethoxy)ethanol. 2-(2-(2-(6-Bromohexyloxy)ethoxy)ethoxy)ethanol was synthesized using the procedure described by Flink. ${ }^{27}$ Fifteen grams of tri(ethylene glycol) (Aldrich, 99\%) and $1.45 \mathrm{~g}$ of $\mathrm{NaH}$ (Acros, 60\% in mineral oil) were dissolved in dry DMF and stirred for $50 \mathrm{~min}$. The resulting solution was treated with $100 \mathrm{~g}$ of dibromohexane (Aldrich, 96\%) and subsequently stirred for 36 h. This mixture was quenched with methanol. After evaporation of the solvent, the resulting oil was dissolved in $250 \mathrm{~mL}$ of $\mathrm{CH}_{2-}$ $\mathrm{Cl}_{2}$, washed four times with water, and dried over $\mathrm{MgSO}_{4}$. Subsequently, the solvent was evaporated and the residue was purified by column chromatography $\left(\mathrm{SiO}_{2}, 2: 1 \mathrm{EtOA} /\right.$ hexane $)$ yielding 2-(2-(2-(6-bromohexyloxy)ethoxy)ethoxy)ethanol (9.624 $\mathrm{g}, 85 \%)$ as verified with ${ }^{1} \mathrm{H}$ NMR and mass spectroscopy.

2-(2-(2-(6-Mercaptohexyloxy)ethoxy)ethoxy)ethanol was synthesized from the previous compound using themethod described by Bader. ${ }^{28}$ 2-(2-(2-(6-B romohexyloxy)ethoxy)ethoxy)ethanol and $13.8 \mathrm{~g}$ of thioureum (Aldrich, 99\%) were dissolved in ethanol and refluxed for $22 \mathrm{~h}$ under a $\mathrm{N}_{2}$ atmosphere. The resulting solution was treated with $2 \mathrm{~g}$ of $\mathrm{NaOH}$ in a few $\mathrm{mL}$ of water and refluxed

(27) Flink S. Sensing Monolayers on Gold and Glass; Twente: Netherlands, 2000.

(28) Bader, M. M. Phosphorus, Sulfur Silicon Relat. Elem. 1996 116,77 


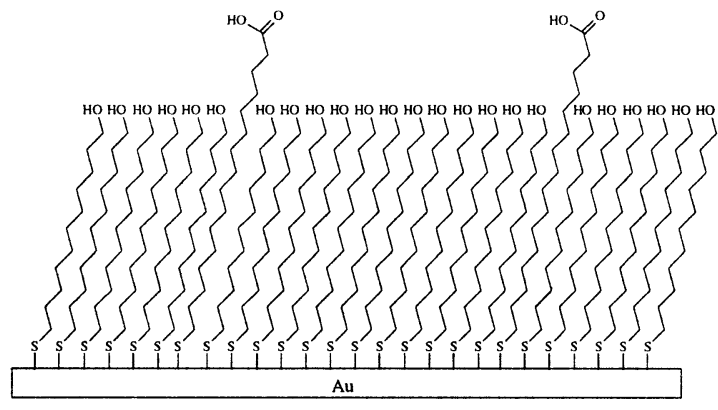

(a)

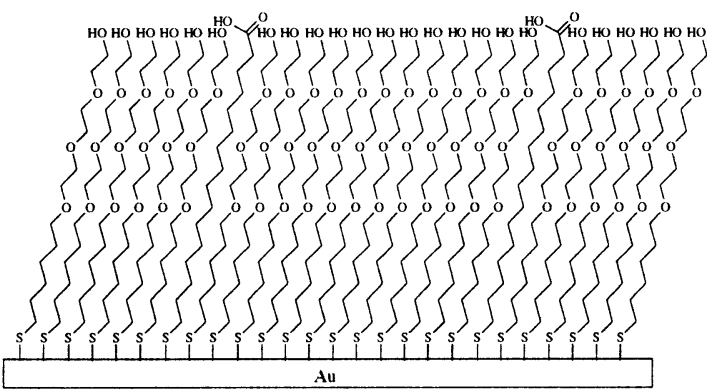

(b)

Figure 1. Schematicrepresentation of themixed SAM s consisting of 16-mercapto-1-hexadecanoicacid and 11-mercapto-1-undecanol, i.e., SAM 1 (a), and of 16-mercapto-1-hexadecanoic acid and 2-(2-(2-(6-mercaptohexyloxy)ethoxy)ethoxy)ethanol, i.e., SAM2 (b).

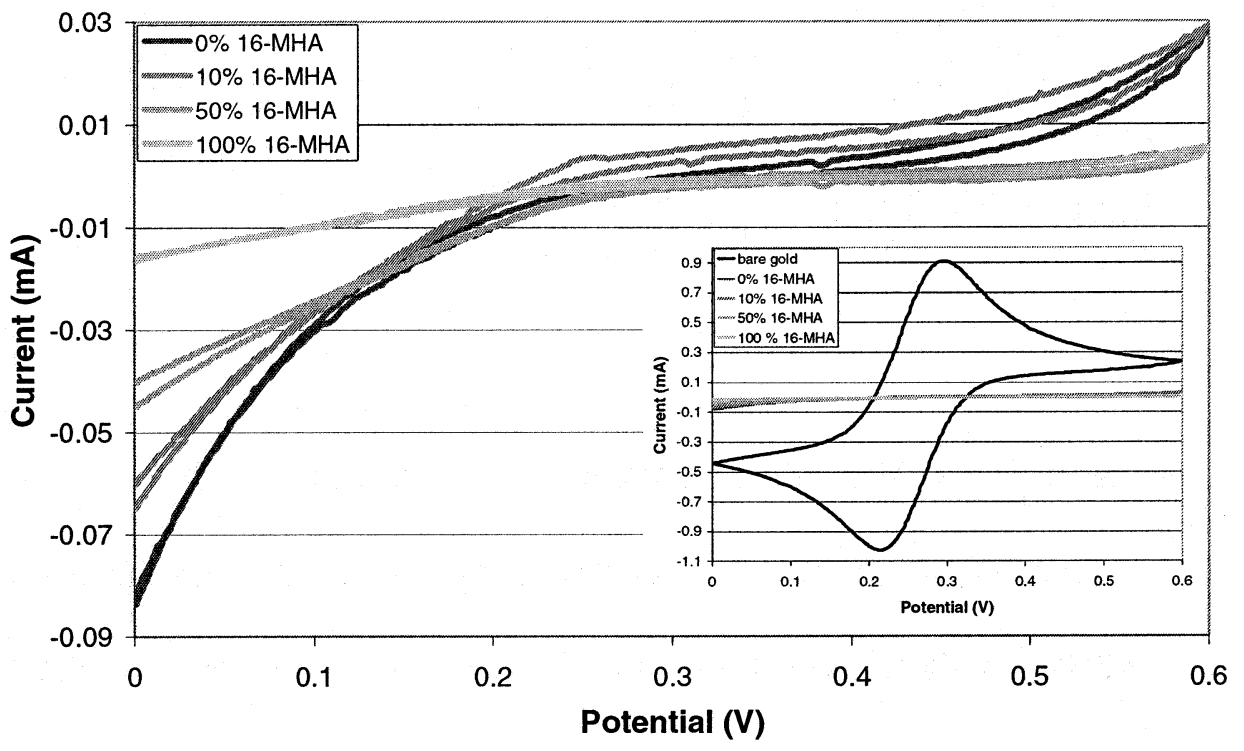

Figure 2. Cyclic voltammograms for different ratios of 16-mercapto-1-hexadecanoic acid and 11-mercapto-1-undecanol in the mixed SAM 1 on the gold electrodes. Measurements were performed in $6 \mathrm{mM} \mathrm{K}_{3} \mathrm{Fe}(\mathrm{CN})_{6}$ in $1 \mathrm{M} \mathrm{KCl}$ with a scan rate of $0.1 \mathrm{~V} \mathrm{~s}^{-1}$.

for an additional $20 \mathrm{~h}$ under a $\mathrm{N}_{2}$ atmosphere. The mixture was then treated with $\mathrm{HCl}$ in ice-cold water, dissolved in $100 \mathrm{~mL}$ of $\mathrm{CH}_{2} \mathrm{Cl}_{2}$, and washed with water. The solvent was evaporated, and the oil-like residue was purified by column chromatography $\left(\mathrm{SiO}_{2}, 15: 1 \mathrm{CH}_{2} \mathrm{Cl}_{2} / \mathrm{MeOH}\right.$ ) giving rise to 2-(2-(2-(6-mercaptohexyloxy)ethoxy)ethoxy)ethanol or 6-PEO (4.16g, $52 \%)$. ${ }^{1} \mathrm{H}$ NMR $\left(300 \mathrm{MHz} \mathrm{CDCl}_{3}\right): \delta=1.38(\mathrm{~m}, 4 \mathrm{H}), 1.60(\mathrm{~m}, 4 \mathrm{H}), 2.52(\mathrm{q}, 2 \mathrm{H})$, 3.09 (br, $1 \mathrm{H}), 3.45(\mathrm{t}, 2 \mathrm{H}), 3.65(\mathrm{~m}, 12 \mathrm{H}) .{ }^{13} \mathrm{C} \mathrm{NMR}(75 \mathrm{MHz}$, $\left.\mathrm{CDCl}_{3}\right): \delta=24.3,25.3,27.9,29.2,33.7,61.4,69.8,70.1,70.3$, 70.3, 71.1, 72.3. MS (Cl): 267.4 $\left(\mathrm{MH}^{+}\right), 151,117 . \mathrm{MS}(\mathrm{EI})(\mathrm{M}+$ $\mathrm{H})=267.16317$ with an el emental composition of $\mathrm{C}_{12} \mathrm{H}_{27} \mathrm{O}_{4} \mathrm{~S}$ and an error of $-0.2 \mathrm{mmu}$.

\section{Results and Discussion}

Surface Characterization of the Mixed SAMs. A schematic presentation of the two mixed monolayers studied, 16-MHA and 11-MUOH (SAM 1) or 16-MHA and 6-PEO (SAM2), is shown in Figure 1. The structural characterization of the monolayers was performed using CV, CA, and GA-FTIR.

The CV resultsillustrated in Figure 2 demonstratethat mixed SAMs of 16-MHA and 11-MUOH form densely packed monol ayers after $3 \mathrm{~h}$ of deposition time. I n addition it is observed that theoxidation/reduction peak separation increases with increasing concentrations of 16-MHA in the mixed SAM1. The higher alkyl chain length of the latter thiol compound probably allows the mixed SAM to become more densely packed, i.e., the redox couple $\mathrm{K}_{3-}$ $\mathrm{Fe}(\mathrm{CN})_{6}$ is further away from theworking el ectrode, which gives risetoa larger peak separation (Figure 2). ${ }^{29} \mathrm{Similar}$ voltammograms have been observed for SAM2.

CA measurements give additional information on the physical properties of the mixed SAM surfaces. The water contact angle of mixed SAM 1 with $5 \%$ of $16-\mathrm{MHA}$ is very small, i.e., $<15^{\circ}$, while the contact angle of mixed SAM 2 (5\%) is found to be $33 \pm 1^{\circ}$. B oth contact angle values are indicative for a hydrophilic surface and correspond very well to reported values for densely packed mixed monolayers with these kinds of end groups. ${ }^{19,30}$ The contact angl efor a blank gold sampleimmersed in ethanol for the same duration was $86 \pm 7^{\circ}$, which is due to the fast recontamination of gold in ambient atmosphere. ${ }^{31}$ The contact angle values for the mixed monolayers have also been calculated by the formula proposed by Bain et al. ${ }^{32}$ and fit perfectly the experimental values for the mixed SAMs.

It is well-known that the $\mathrm{CH}$ stretching vibration modes of the alkyl chains in the SAM are very sensitive to the packing density and to the presence of gauche defects, which makes them ideally suited as probes to determine theSAM quality. ${ }^{12}$ In particular, the antisymmetric $\mathrm{CH}_{2}$

(29) Cheng, Q.; Brajter-Toth, A. Anal. Chem. 1995, 67, 2767.

(30) Ulman, A. Thin Films, Self-Assembled Monolayers of Thiols; Academic Press: San Diego, CA, 1998; Vol. 24.

(31) Gaines, G. L., J r. J. Colloid Interface Sci. 1981, 79 (1), 295.

(32) Bain, C. D.; Troughton, E. B.; Tao, Y.-T.; Evall, J .; Whitesides, G. M.; Nuzzo, R. G. J . Am. Chem. Soc. 1989, 111, 321. 
stretching vibration $\left(v_{a}(\mathrm{C}-\mathrm{H})\right)$ is a useful indicator, since its position varies from 2916 to $2917 \mathrm{~cm}^{-1}$ for SAMs of exceptional quality or cooled below room temperature, via $2918 \mathrm{~cm}^{-1}$ which is thenormal valuefor a high-quality SAM, to $\sim 2926 \mathrm{~cm}^{-1}$, which is indicative of a heavily di sordered, "spaghetti-like" SAM. In this study, $v_{a}(\mathrm{C}-\mathrm{H})$ values of 2920, 2920, and $2923 \mathrm{~cm}^{-1}$ are observed for the homogeneous SAMs of 16-MHA, 11-MUOH, and 6-PEO, respectively. Thesevalues indicate that the homogeneous SAMs of 16-MHA and 11-MUOH exhibit an acceptable quality whilethe homogeneous SAM of 6-PEO is of minor quality, probably due to the shorter alkyl length (6 C atoms). The $v_{\mathrm{a}}(\mathrm{C}-\mathrm{H})$ values observed for mixed SAM 1 and mixed SAM2 are 2921 and $2924 \mathrm{~cm}^{-1}$, respectively. Mixed SAM1 still exhibits an acceptable quality, while SAM 2 is rather disordered.

Surface Plasmon Resonance Characterization. The aim of the surface plasmon resonance (SPR) experiments is to show the advantage of the use of mixed SAMs compared to homogeneous SAMs. Tothisend, wedeposited SAM s consisting of $100 \% 16-\mathrm{MHA}$, a $1 / 9$ ratio of $16-\mathrm{MHA} /$ $11-\mathrm{MUOH}$ (SAM 1 ), and a $1 / 9$ ratio of $16-\mathrm{MHA} / 6-\mathrm{PEO}$ (SAM2). The SPR signal for anti-HSA before and after immobilization on the homogeneous and themixed SAM S is evaluated. In addition, we al so checked the adsorption of $10 \mu \mathrm{g} / \mathrm{mL}$ of a nonspecific human I gG reagent in order to evaluate the performance of the SAMs with regard to nonspecificadsorption. Theactivation step was performed with $0.2 \mathrm{M}$ EDC and $50 \mathrm{mM}$ NHS.

The anti-HSA immobilization degree is found to be $1376 \pm 5 \mathrm{RU}$ on the homogeneous 16-MHA SAM, $1506 \pm$ 32 on themixed SAM 1 , and $1403 \pm 79$ on the mixed SAM 2. The immobilization is higher on mixed SAM 1 compared tothehomogeneous 16-MHA SAM. Thelevel of nonspecific adsorption, which is the adsorption (of I gG reagent) on a SAM surface without antibodies, is less than $3 \mathrm{RU}$ on the mixed SAM1 and mixed SAM2, which is undetectable above the baseline noise. The increase in antibody immobilization on the mixed SAMs is probably due to sterichindranceon the homogeneousSAMs. ${ }^{33,34}$ Thelonger "spacer arm" of the carboxylic group of 16-MHA in the mixed SAM 1 makes this carboxylic group moreaccessible, and as a consequence it can bind more antibodies than a homogeneous SAM. In the homogeneous SAM, the carboxylic group is i mbedded in a two-dimensi onal structure and therefore less accessible for activation via the EDC/ NHS method and/or for immobilization of antibodies.

Phase separation is often seen in mixed SAMs. The dimensions of the separated phases differ a lot depending on the headgroup and the length difference between the thiols in the mixed SAMs. Our atomic force microscopy measurements could not reveal any phase separation of the mixed SAMs on the evaporated J 1 gold surface (not atomically flat). However the reported phase separation dimensions are mainly small. $35-40$ Therefore we expect that the antibodies with a diameter of $14 \mathrm{~nm}$ are not

(33) Spinke, J .; Liley, M.; Guder, H.-J .; Angermaier, L.; Knoll, W. Langmuir 1993, 9, 1821.

(34) J ung, L. S.; Nelson, K. E.; Stayton, P. S.; Campbell, C. T. Langmuir 2000, 16 (24), 9421.

(35) Shon, Y.-S.; Lee, S.; Perry, S. S.; Lee, T. R. J . Am. Chem. Soc. 2000, 122, 1278

(36) Stranick, S. J .; Atre, S. V.; Parikh, A. N.; Wood, M. C.; Allara, D. L.; Winograd, N.; Weiss, P. S. Nanotechnology 1996, 7, 438.

(37) Chen, S.; Li, L.; Boozer, C. L.; J iang, S. Langmuir 2000, 16, 9287.

(38) Mizutani, W.; Ishida, T.; Tokumoto, H. Appl. Surf. Sci. 1998, $130-132,792$.

(39) Shevade, A. V.; Zhou, J .; Zin, M. T.; J iang, S. Langmuir 2001, $17,7566$.

(40) Li, L.; Chen, S.; J iang, S. Langmuir 2003, 19 (3), 666.

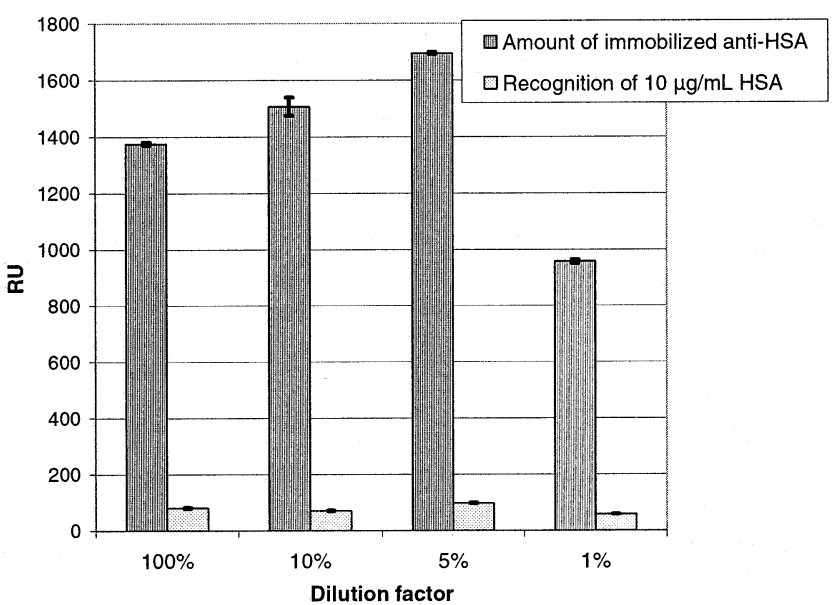

Figure 3. SPR signals for the covalent coupling of anti-HSA (from $500 \mu \mathrm{g} / \mathrm{mL}$ in $10 \mathrm{mM}$ acetate buffer $\mathrm{pH}=5$ ) onto mixed SAM 1 and the recognition of $10 \mu \mathrm{g} / \mathrm{mL}$ HSA (in HBS buffer) by the immobilized anti-HSA versus the dilution factors of 16MHA in the mixed 16-MHA/11-MUOH alkylthiol mixture (in ethanol solution) used to prepare the monolayer. Error bars indicate the absolute standard deviation of at least two lines on at least two samples.

affected by the possible phase separation of the two thiols. Moreover, possiblephaseseparation causes nosignificant variation in immobilization degree; i.e., the standard deviations on the different measurements on mixed SAM 1 is small (see further).

In a next step, we varied the amount of thiols with carboxylic groups compared to the thiols against nonspecific adsorption for SAM 1. I t is cl ear that all anti body/ antigen binding processes at the surface must be specific ones only and should occur with maximum efficiency. This implies that thequantity of antibodies bound tothesurface should be maximized, while the extent of nonspecific adsorption is minimized. Only SAM 1 was chosen for this optimization process because it has a higher structural quality than SAM2, because it consists of commercial thiols, and because there is no significant difference in the performance of SAM1 and SAM2 with regard to antibody immobilization and nonspecific adsorption (see above). The anti-HSA immobilization degree, the recognition signals for different concentrations of HSA, and the nonspecificsignals for IgG wereevaluated. TheSPR signal for the antibody immobilization and the recognition of one of the HSA concentrations ( $10 \mu \mathrm{g} / \mathrm{mL})$ are shown in Figure 3. Theoptimizati on process was started with $100 \%$ $16-\mathrm{MHA}$, followed by $10 \%, 1 \%$, and $5 \%$. The opti mization was performed on twolines on two different samples with the given standard deviation as a result. It is observed that both the immobilization of anti-HSA and the recognition of $10 \mu \mathrm{g} / \mathrm{mL}$ of HSA appear to be the highest for the $5 \%$ mixed SAM 1 . The nonspecific adsorption of IgG on the 5\% SAM is al ways lower than $5 \mathrm{RU}$ and therefore insignificant. In conclusi on, a mixture consisting of $5 \%$ of 16-M HA in a matrix of $95 \%$ of $11-\mathrm{MUOH}$ can beconsidered as optimal for obtaining the highest degree of antibody immobilization. In addition, the 5\% SAM 1 appears to be ideal to prevent nonspecificadsorption, sinceit represents the largest amount of thiols with $\mathrm{OH}$ end groups without loss of antibody binding capacity.

In a further stage, we applied two types of random coupling procedures to homogeneous and mixed SAM 1. The first one is a one-step covalent coupling based on an EDC - NHS activation, which couples the $\mathrm{NH}_{2}$ groups of Iysine moi eties in theantibody to theactivated carboxylic group of themixed SAMs. ${ }^{6}$ The second coupl ing procedure 


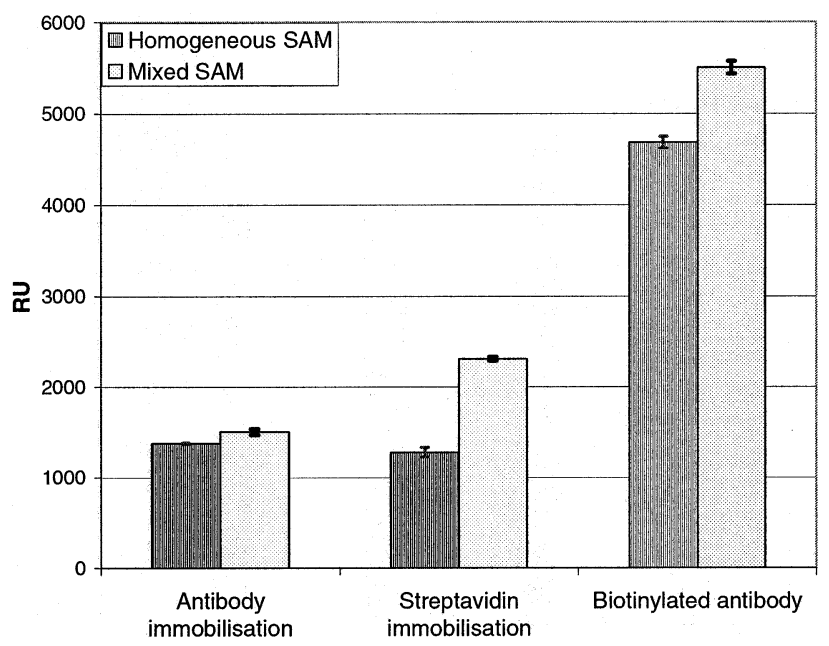

Figure 4. SPR signals for the covalent coupling of anti-HSA, streptavidin $(500 \mu \mathrm{g} / \mathrm{mL}$ in $10 \mathrm{mM}$ acetate buffer $\mathrm{pH}=5)$ and biotinylated anti-HSA ( $500 \mu \mathrm{g} / \mathrm{mL}$ in HBS buffer) onto mixed SAM 1 or onto a homogeneous SAM of 16-MHA. Error bars indicate the absolute standard deviation of at least two lines on at least two samples.

is an indirect coupling procedure using streptavidin and biotin. Streptavidin is a tetramer containing four identical subunits with a molecular mass of $15 \mathrm{kDa}$. Each subunit possesses onehigh-affinity binding sitefor biotin (vitamin $\mathrm{H})$. The dissociation constant of approximately $10^{-15} \mathrm{M}$ is undisturbed by extremes of $\mathrm{pH}$, buffer salts, and even chaotropic agents. ${ }^{6}$ This kind of coupling is therefore universally applicableand very stable. After theactivation of the carboxylic group of the mixed SAMs with EDCNHS, streptavidin $(500 \mu \mathrm{g} / \mathrm{mL})$ is covalently coupled to the surface. In a next step biotinylated anti-HSA (500 $\mu \mathrm{g} / \mathrm{mL}$ ) is i mmobilized on thestreptavidin-coated surface. The SPR results show that the immobilization of antiHSA, theimmobilization of streptavidin, and the binding of biotinylated anti-HSA are clearly the highest on the mixed SAMs (Figure 4). Ther efore, these results again indicatetheenhanced qual ities, which can beachieved by using mixed SAMs.

The stoichiometry of the binding of biotinylated antiHSA tostreptavidin can becal culated using the mol ecular mass values for streptavidin (60 kDa) and biotinylated anti-HSA (150 kDa) and their immobilization degree. It is found that the binding stoichiometry on the homogeneous SAM is somewhat higher than that on the mixed SAM, i.e., 1.46 compared to 1.05. The low experimental stoichiometry compared to the theoretical value (i.e., 4) is probably due to steric hindrance. Since streptavidin is covalently immobilized on the surface, one cannot expect a large binding stoichiometry for large antibodies ( 14 $\mathrm{nm}$ ) to the small binding sites of the small streptavidin molecules $(\sim 5 \mathrm{~nm})$. Sincemorestreptavidin can becoupled on themixed SAM 1, onecan immobilize morebiotinylated anti-HSA despite the lower stoichiometry for the mixed SAM 1.

In real diagnostic applications a specific analyte must be detected in the presence of a higher amount of nonspecific analytes. To investigate this, we spiked the analyte of inter est, i.e., HSA, with a higher concentration of a nonspecific analyte, i.e., IgG. Figure 5 shows the recognition of HSA by randomly immobilized anti-HSA (using EDC-NHS) on SAM1. One can observe that the recognition signal is very similar for the sample with or without nonspecific analytes. These results demonstrate that SAM 1 is excellent for real biological applications.

Quantitative Information. Semiquantitative calcu- lations can yield information on theamount of antibodies bound on the surface. One may consider the antibody to be a lens-shaped spheroid and densely packed in upright or in down-lying position. Depending on this difference, a monolayer of antibodies on the surface represents between 1.3 and $6.5 \mathrm{mg} / \mathrm{m}^{2} .41,42$ Since $\Delta R U=1000$ corresponds to $1 \mathrm{mg} / \mathrm{m}^{2}, 25,26$ an antibody monolayer should result in a RU value between 1300 and 6500. The immobilization degree observed in Figure 4 varies between 1376 RU and 5502 RU depending on the SAM and the coupling procedure used. This implies that the antibodies exhibit a packing structure between a monolayer of antibodies in down-lying position and an incomplete coverage of antibodi es in upright position (henceless area per antibody).

A standard curve was generated in order to calculate the detection limit (data not shown). Different concentrations of HSA were sent over the immobilized anti-HSA surface, and this binding event was regenerated with 10 $\mathrm{mM}$ of glycine $\mathrm{pH}$ 2.2. These experiments revealed that the decrease in antibody activity or stability is only $8 \%$ after 14 regeneration cycles (data not shown). The linear range is found to be between 0 and $100 \mathrm{ng} / \mathrm{mL}$. The detection limit ${ }^{43}$ is calculated to be $3 \times(\mathrm{SD} / \mathrm{S})=3 \times$ $(0.2222 / 0.3123)=2.1 \mathrm{ng} / \mathrm{mL}$, with SD the standard deviation on 10 blank injections and $\mathrm{S}$ the slope of the standard curve. This value is very small for this kind of system (Biacore 2000) in combination with mixed SAMs.

Comparison with a Commercial Layer. The mixed and homogeneous SAMs were compared with the commercial carboxymethylated dextran surface (CM5-chip) of Biacorewith regard toanti body immobilization, antigen recognition, and nonspecific adsorption. On all surfaces, $500 \mu \mathrm{g} / \mathrm{mL}$ anti-HSA was immobilized. Different concentrations of HSA $(1 \mathrm{ng} / \mathrm{mL}$ up to $100 \mu \mathrm{g} / \mathrm{mL})$ and $10 \mu \mathrm{g} / \mathrm{mL}$ of a nonspecific analyte such as IgG were sent over the surface-immobilized anti-HSA (Figure 6). These experimental data clearly show that the different surfaces and coupling procedures result in a similar sensitivity for the detection of a lower concentration of HSA ( $100 \mathrm{ng} / \mathrm{mL})$. As opposed to these lower concentrations, the signal of the CM-5 chip is much higher for the higher concentrations of HSA $(10 \mu \mathrm{g} / \mathrm{mL})$ because of the three-dimensional dextran structure on this chip and its higher capability to bind antibodies (14626 $\pm 133 \mathrm{RU}$ ). To our opinion, this difference in antibody immobilization (88\% lower on the mixed SAM 1) is compensated (for lower concentrations) by the limited thickness of the thiol monolayers, giving rise to similar recognition signals and similar sensitivity for lower concentrations of HSA detection. More specifically the CM- 5 chip consists of dextran chains attached to a thiol monolayer, the gl obal thickness being around $100 \mathrm{~nm} .{ }^{44}$ Thethiol monolayers of SAM 1 , on the contrary, aremuch thinner $(1.45-2.25 \mathrm{~nm})$ sothat thebinding event occurs much closer tothesurface. Indeed, surfaceplasmons are electron clouds, which behave as if they were single charged particles. Part of their energy is expressed as oscillations in the plane of the metal surface, which generates an el ectric fiel d extending about $100 \mathrm{~nm}$ above and below the metal surface, decaying exponentially as a function of the distance. ${ }^{2}$ It is therefore clear that SPR measurements will be more sensitive to binding events

(41) Esser, P. Nunc Bull. 1997, 6 (1), 1

(42) Kim, M.; Saito, K.; Furusaki, S.; Sugo, T.; I shigaki, I. J. Chromatogr. 1991, 586, 27.

(43) Snyder, L. R. Practical HPLC method devel opment; J ohn Wiley \& Sons: New York, 1997

(44) Löfås, S.; J ohnsson, B. J . Chem. Soc., Chem. Commun. 1990, 1526. 


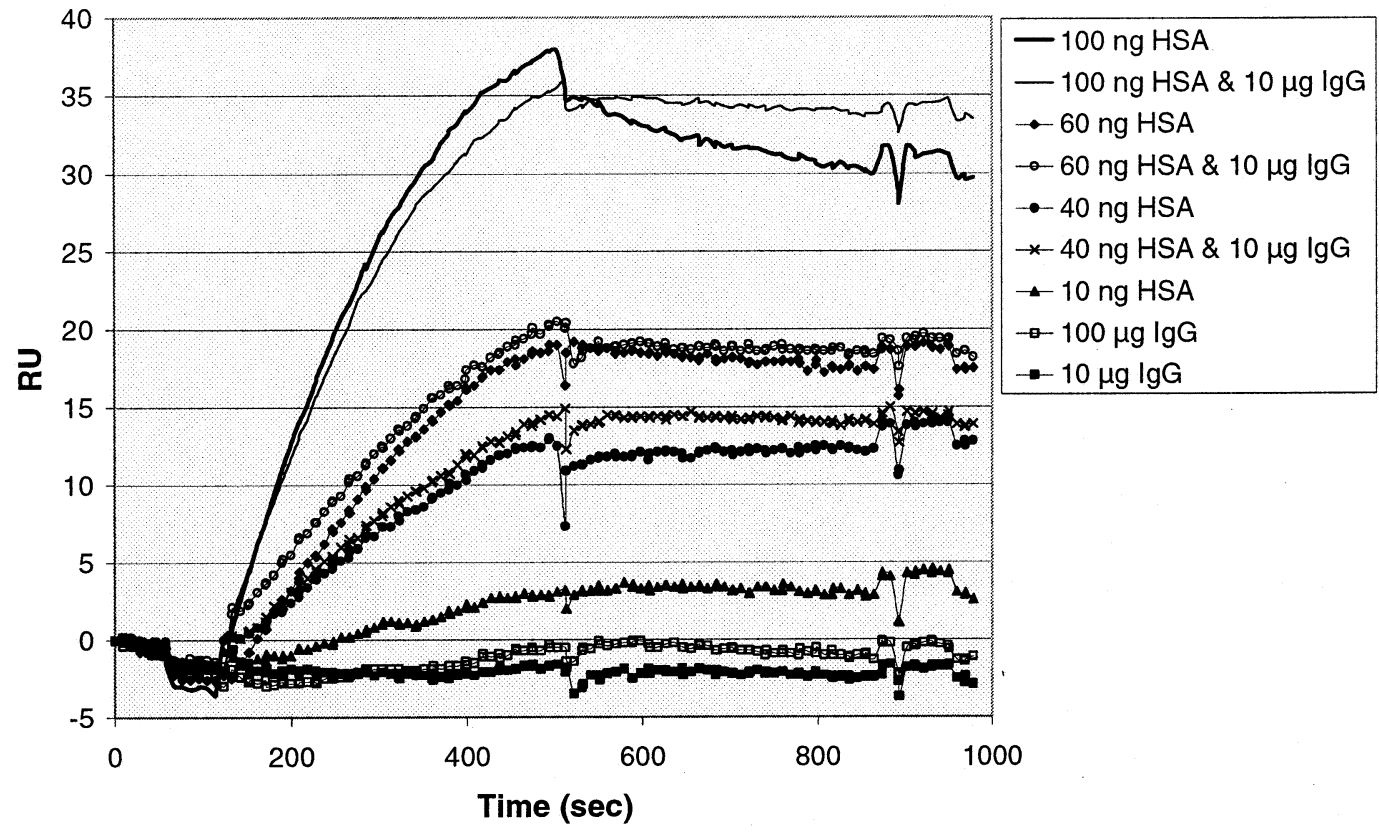

Figure 5. Surface plasmon resonance sensograms showing the association and dissociation of different concentrations of HSA and of HSA spiked with I gG on a mixed SAM 1 covered with anti-HSA. The recognition of a nonspecific analyte (I gG) is also shown.

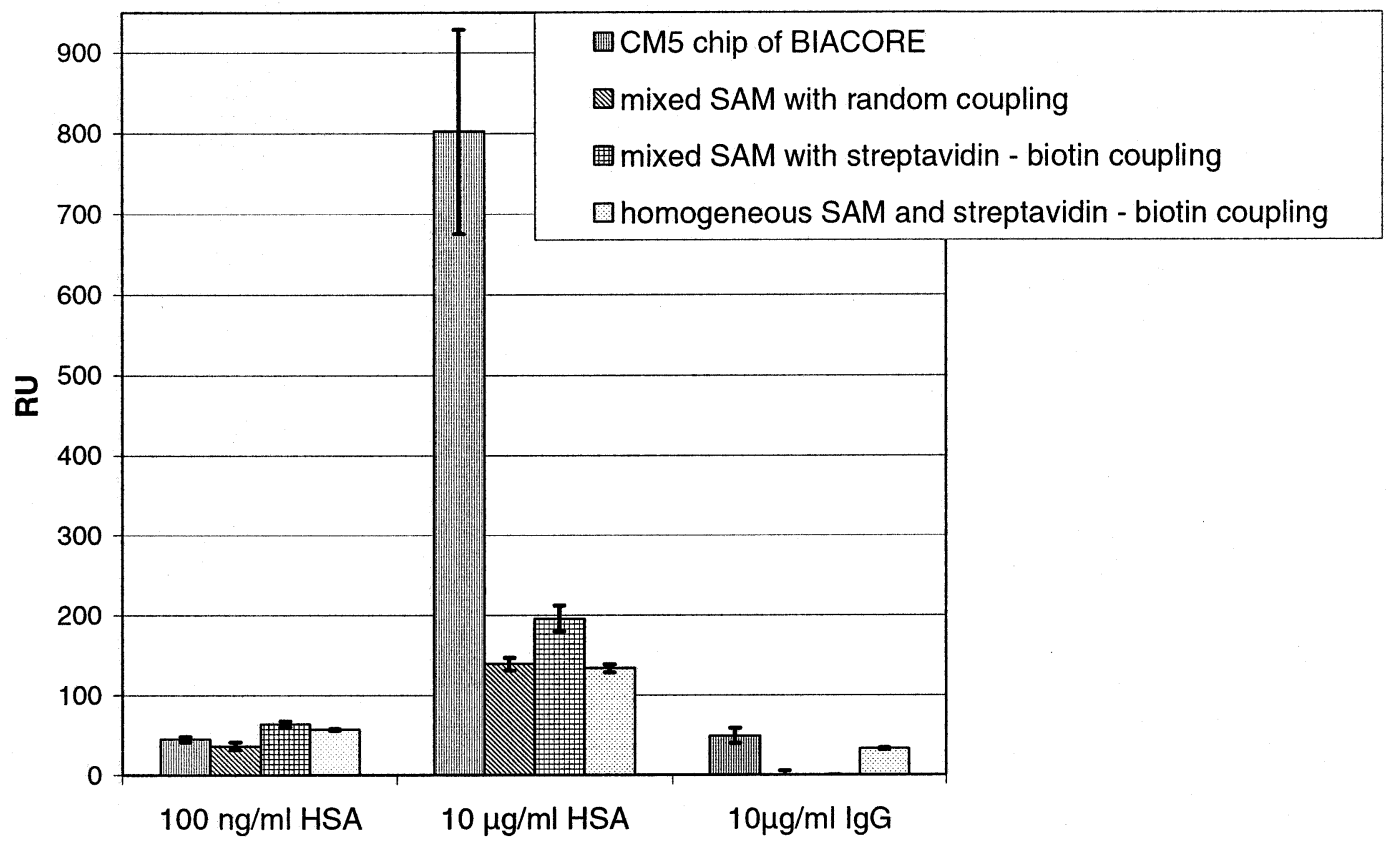

Figure 6. Surface plasmon resonancesignals for therecognition of $100 \mathrm{ng} / \mathrm{mL}$ of HSA, $10 \mu \mathrm{g} / \mathrm{mL} \mathrm{HSA}$, and $10 \mu \mathrm{g} / \mathrm{mL}$ of a nonspecific analyte (I gG) on different surfaces and different anti-HSA coupling procedures. E rror bars indicatethe absolute standard deviation of at least two lines on at least two samples.

occurring closer to the surface. Although the signals for lower concentrations of HSA (100 ng/mL) are comparable for all surfaces, the signal for the nonspecific adsorption of $10 \mu \mathrm{g} / \mathrm{mL}$ of I gG is comparable to the signal observed for $100 \mathrm{ng} / \mathrm{mL}$ of the specific antigen, i.e., HSA, for both the homogeneous SAM or the CM-5 chip. As a consequence, it is not possible to discriminate between a low concentration of a specific analyte in the presence of an excess of nonspecificspecies using the CM -5 chi p or a homogeneous SAM, which is a major drawback for real diagnostical applications. Contrary to this, themixed SAM 1 can easily discriminate $100 \mathrm{ng} / \mathrm{mL}$ of $\mathrm{HSA}$ from an excess of nonspecific analyte. In addition, the drift on the basel ine signal is quite high for the CM-5 chip (drift of $2428 \mathrm{RU}$ over $4.5 \mathrm{~h}$ ), which is a large disadvantage for quantitative measurements. Thesedrawbacks can beavoi ded by using the mixed SAMs (drift of $64 \mathrm{RU}$ over $4.5 \mathrm{~h}$ ) in combination with either the direct or the indirect random coupling procedure.

An added advantage of the mixed SAM 1 concerns the reliability of the binding kinetics. Toassess this intomore detail, the same RU signal of anti-HSA was immobilized on the CM5-chip and on the mixed SAM1. Subsequently we monitored the recognition of different concentrations of HSA. In Figure 7 the recognition of $200 \mathrm{ng} / \mathrm{mL}(2.94$ nM) HSA normalized at the maximum response is shown on both the CM5-chip and the mixed SAM 1. The normalized response curves as function of time give a good estimation of the mass transport limiting factor. ${ }^{45}$ The change of thesensor response is faster on the mixed SAM 1 


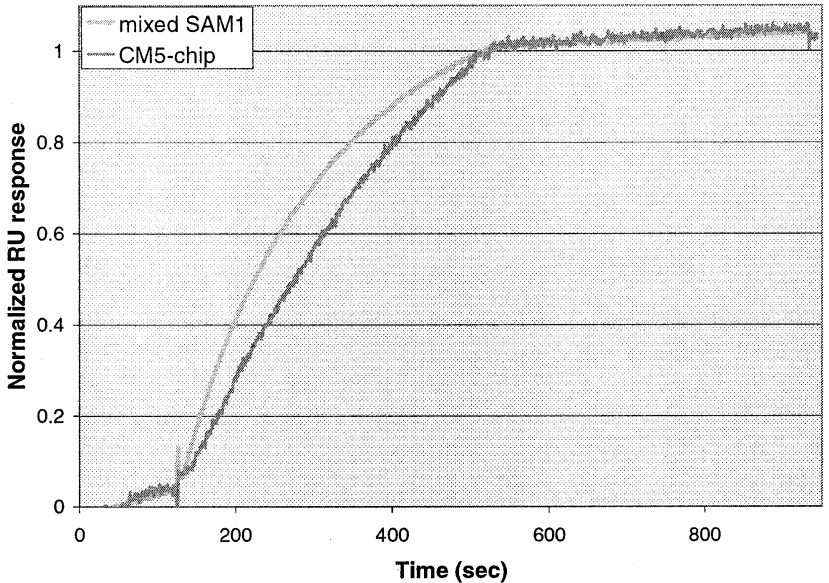

Figure 7. The association and dissociation of $200 \mathrm{ng} / \mathrm{mL}(2.94$ $\mathrm{nM}$ ) of HSA by the immobilized anti-HSA on both the CM5chip and the mixed SAM 1 . These curves are normalized at the maximum response.

compared to the CM5-chip, which implies that the CM5chip is more mass transport limited. Therefore the apparent kinetic parameter will be underestimated on theCM5-chip. This is probably duetotheslower transport step of the antigens to theimmobilized anti-HSA because of the three-dimensional dextran structure on this chip, which gives rises to effects of gel partitioning and aggregation induced by high local steric hindrance. ${ }^{45-47}$

\section{Conclusion}

In this paper mixed self-assembled monolayers are studied in which two functionalities are simultaneously incorporated on the gold surface. These SAMs were characterized with CV, CA, and GA-FTIR. The SAM coverage was found to be adequate, and the structural properties and physical properties were demonstrated. The properties of the mixed SAMs fulfill the necessary requirements for making stable and well-ordered mixed SAMs. Their use as an affinity biosensor interface for immunosensor applications was evaluated usingSPR. The

(45) Muguruma, H.; Nagata, R.; Nakamura, R.; Sato, K.; U chiyama, S.; Karube, I. Anal. Sci. 2000, 16, 347.

(46) Schuck, P. Curr. Opin. Biotechnol. 1997, 8, 498.

(47) Myszka, D. G. Curr. Opin. Biotechnol. 1997, 8, 50. amount of the different components in the mixed SAMs was optimized with regard to antibody immobilization, antigen recognition, and nonspecific adsorption. It was found that a mixed SAM deposited from a mixed solution of $5 \%$ of $16-\mathrm{MHA}$ and $95 \%$ of $11-\mathrm{MUOH}$ exhibits the most favorable properties. The indirect and direct coupling of biomolecules to mixed SAM s was evaluated. In addition, the enhanced qualities of this mixed SAM compared to the commercially available dextran layer of Biacore were assessed. Quantitative information about the antibodies immobilized on themixed SAM surface, the detection limit of mixed SAM 1 in combination with a Biacore ${ }^{\circledR} 2000$ system, and the stoichiometry of the antibody/antigen binding events were interpreted.

The ability to tune surface properties with regard to antibody immobilizations, recognition signals, and nonspecific adsorption with mixed SAMs has been demonstrated. Their stability and their excellent qualities concerning nonspecific adsorption makethem very useful as a basis for the development of affinity biosensor interfaces for real diagnostical applications or immunosensors. The sensor platform used in this study is the surface plasmon resonance system of Biacore, but there is no restriction to use other sensors in combination with the affinity biosensor interface based on mixed SAMs of thiols. Almost every sensor with a gold surface can be used to monitor the antigen-antibody interaction and can benefit from the enhanced qualities of themixed SAM approach.

Acknowledgment. The authorsthank D. Schwendel, S. Herrwerth, and Professor M. Grunze of the University of Heidel berg for their kind gift of the deuterated thiols. Professor L. Heerman and W. Maes of the KU Leuven are acknowledged for the useful discussion, and the IWT (Instituut voor de Aanmoediging van Innovatie door Wetenschap en Technol ogie in Vlaanderen) is gratefully acknowledged for its financial support.

Supporting Information Available: Graphs showing the stability of the antibody and the standard curveto cal culate the detection limit and cyclic voltammetry data for mixed SAM 2 on gold. This material is availablefree of chargevia the Internet at http://pubs.acs.org.

LA026908F 